\title{
Energy Paradox: Simulation and Policy Recommendations for the Case of Solar Water Heater
}

\section{Omar Jridi*}

Faculty of Economic Science and Management of Sousse, Sousse University, Erriadh city - 4023 Sousse - Tunisia

\begin{abstract}
The objective of this paper is crystallized around the explanation of the energy paradox, that of the non adoption of cost-effective energy-saving investments. The latter is mutually driven by two major factors. Uncertainty future benefits of energy savings, which we assume that they follow a geometric Brownian motion. In this stochastic process, we take into account the lower costs of efficient equipment as a result of learning by doing. To affirm the robustness of the model, we generate simulation results for the case of solar water heaters. The minimum rate of return required by households reached $18.81 \%$. Beyond that, the model allows the simulation of the effects of the instruments of energy policy oriented to the promotion of the adoption of this equipment. We urge policymaker's ineffectiveness of the policy of subsidy to the purchase of energy-saving equipment and the effectiveness of energy taxation policy. The combination of these two instruments amplifies the adoptions of these devices and generates very positive externalities in terms of energy saving and emission reduction of greenhouse gases.
\end{abstract}

Keywords: Energy efficiency gap; Hurdle rate; Experience curve; Stochastic model

\section{Introduction}

An energy-saving investment is profitable if the present value of energy savings generated over the use duration of the equipment exceeds the investment cost. However, engineers' questions, around the 70's about the non adoption of profitable energy-saving investment, pushed economists to break with the traditional evaluation approach of the profitability of these investments. This inhibition has been extensively discussed in the literature as the energy paradox [1,2]. Statically, this paradox is measurable via the gap between real adoptions and under estimates according to the engineers' standards. This adoption gap is often known as the energy efficiency gap [3].

Empirically, several studies consistently show that households are reluctant to adopt an energy-saving investment and require, consequently, too high discount rates in their investment decisions. It is in this sense that Jaffe and Stavins [4] reformulated the paradox of the adoption of profitable energy-saving investment as the observation of higher discount rates than the economy interest rates.

Relatively to the existing literature [5,6], our main contributions is crystallized around the development of new stochastic modeling approach that consists in internalizing and measuring the weight of the factors explaining the energy paradox, as well as the estimation of the required rate of return. Beyond that, the model constructed gives the possibility of careful simulations on the effects of the instruments of energy policy. The rest of the paper is organized as follows. Section 2 presents the methodology of modeling. Sections 3 and 4 lay out, respectively, the stochastic model and key empirical findings. Subsequently, we discuss the effects of policy instruments in Section 5 and conclude in Section 6.

\section{Literature Review}

Breaking with conventional approaches for evaluating the profitability of investments, we claim that a representative agent decided to postpone a profitable energy-saving investment in order to maximize future benefits of energy savings. The formalization of this decision process is based on the rationalization of what it seems irrational behavior, assuming that a potential investor's interest to postpone this investment as a result of three factors. The irreversibility of the investment cost (purchase price plus charges for equipment's installation). The uncertainty of the energy saving benefits (energy price). The self-sustaining decrease of equipments' costs depending on the effect of learning by doing. The specific feature of this function is that it reflects the reduction in production costs at a constant percentage, every doubling of cumulative production [7].

To account for the effect of the latter explicit fawn factor, our first deepening is based on two sequential proposals. The first is technical, which is to express the decrease of costs in a time dimension and not according to the doubling of cumulative production equipment. The internalization of this temporal dynamics is only possible with the provision of temporal data spread on cumulative sales of these innovative equipments. To overcome this drawback of the availability of data, the second proposal is an empirical one. It is to adjust the pattern of cumulative future adoptions by intentions of equipment's adoptions. To do this, we are inspired by diffusion theory of technological innovations, initiated by Roger $[8,9]$, and the main empirical applications of Bass $[10,11]$.

At this level, we note that the energy-saving benefits are assessed over time under the effect of the three factors mentioned above. In this context, a representative agent adopts energy-saving equipment if, and only if the present value of future energy savings flow equals or exceeds its critical threshold for which the optimal option value is reached.

However, with such a formalization of the problem, once the monetary value of energy savings increase and reach the expectations of potential investors, they invest all simultaneously, as they have the

*Corresponding author: Omar Jridi, Faculty of Economic Science and Management of Sousse, Sousse University, Erriadh city - 4023 Sousse - Tunisia, Tel: +21620512885; E-mail: jridi.omar@yahoo.fr

Received June 02, 2017; Accepted June 12, 2017; Published June 19, 2017

Citation: Jridi O (2017) Energy Paradox: Simulation and Policy Recommendations for the Case of Solar Water Heater. J Environ Anal Toxicol 7: 480. doi: 10.4172/21610525.1000480

Copyright: ( 2017 Jridi O. This is an open-access article distributed under the terms of the Creative Commons Attribution License, which permits unrestricted use, distribution, and reproduction in any medium, provided the original author and source are credited. 
same option value. The current structure of the model break, so with the fundamentals of technology innovation diffusion theory, according to which the diffusion process follows a sigmoid trajectory: the adoption rate is slow at first (with the adoption of innovators), begins to increase exponentially, bowing from a point of inflection towards a concave trajectory up to saturation (with the adoption of the stragglers) See Ref [8-11] for a literature review.

Faced to this problem, the second deepening of this model is to introduce more realism to the equipments' diffusion processes [12]. The gain in energy savings varied substantially depending on contextual factors related to housing, such as the type of housing and occupancy status and depending on the socioeconomic characteristics of households, such as the communal areas and the level of education [13].

Ultimately, the dynamics of the model is as follows: first adopters (the innovators) are those with the highest energy saving potential. With high performance, these investors did not have high profitability requirements and do not delay the investment too much. In other words, these investors have the lowest optimal option value, which achievement does not require a lot of waiting. The last adopters (latecomers) are those with the lowest potential of energy saving, or the lowest energy saving benefits. By requiring higher benefits, these households are delaying the adoption, anticipating future appreciations of such benefits. In other words, these potential investors have the highest option values whose achievement requires a wait for future appreciations of the energysaving benefits.

\section{Modeling Approach}

\section{Effect of learning by doing in energy efficient equipment}

Learning curve approach consists in the expression of the cost of production according to cumulative production. The specific feature of this function is that it reflects the decline of costs of production, in constant percentage, with each doubling of cumulative production [2]. This approach has been widely used for the prediction of energy savings generated by energy efficient equipment. According to Weiss [2], much of the literature approximates the effect of experience on improving energy efficiency by decreasing costs of the equipment [14,15]. Formally, the learning curve takes the following form:

$$
C=C_{0}(X)^{b}
$$

$X$ refers to the cumulative production technology, $C_{0}$ represents the cost of the equipment of the first unit adopted and $C$ the cost of related equipment at the cumulative production $X$. The coefficient bis the experience index $(b<0)$.

Particular attention should be paid to the representation of process costs. According to the approach of the experience curve, costs evolutions is a function of the cumulative level of adoption, so that previously we seek cost trends over time. To add the time dimension to the Equation 1 , our technique is to adjust the pattern of cumulative adoptions by the intention of adoptions of such equipment. To do this, we draw on the theory of diffusion of innovations initiated by Roger [8,9] and empirical applications of Bass [10,11].

According to the Bass model, we use the following differential equation to adjust the diffusion process of equipments:

$$
d X(t) / d t=\left[p+\frac{q}{M} X(t)\right][M-X(t)]
$$

With $X(\mathrm{t})$ denotes the intentions of equipment adoption in year $\mathrm{t}, \mathrm{p}$ and $\mathrm{q}$ are, respectively, the coefficient of innovation and imitation and $\mathrm{M}$ is the total potential adopters coefficient (a proxy of the target population). According to this specification we adjust the trend intentions to adopt the following logistic distribution function:

$$
X(t)=M \frac{1-e^{-(p+q) t}}{1+\frac{q}{p} e^{-(p+q) t}}
$$

Note that the goal of this proposal is to apply the lessons of the literature on the diffusion of innovations, affixing the reactivity of equipment costs to cumulative adoptions to intentions of adoptions that relieves from estimates of the Bass model. Subsequently, we reset the Equation 1, replacing the cumulative adoptions by the intentions of cumulative adoptions:

$$
C_{t}=C_{0}\left(X_{t}\right)^{b}
$$

Ultimately, through the explicit integration of the dynamics of the learning curve in the process of changing costs of CED equipment, we setup, in percentage, the trend of the evolution of these costs as follows:

$$
\gamma c=\frac{d c_{t}}{d t} \frac{1}{c_{t}}
$$

Once we register the evolution of the costs in the dynamics of learning by doing, our model helps to explain the first pattern of the energy paradox. In this context, agent now postpones the profitable investment decision in the CED in order to benefit from the opportunity to have a lower ex-ante cost under the effect of learning by doing.

\section{Benefit of energy saving in geometric Brownian motion}

In the second factor explaining the energy paradox, we postulate that the option value for a potential investor is measured with uncertainty about future evolutions in equipment costs and energy prices. Indeed, if the volatility of these two variables is zero, the option will be worthless because a potential investor has the clarity to know with certainty whether an investment made today will be profitable tomorrow. In contrast, with high volatility, the option value is assessed if an investor expects future increases in energy prices and/or the future cost reduction of the equipment. Formally, we incorporate uncertainty about the evolution of equipment costs and energy prices assuming that they follow a geometric Brownian motion. Over time, the evolutions of these two variables follow, respectively, the following processes:

$$
\begin{aligned}
& d C_{t} / C_{t}=\gamma_{C} d t+\sigma_{C} d z_{C} \\
& d P_{t} / \mathrm{P}_{t}=\gamma_{P} d t+\sigma_{P} d z_{P}
\end{aligned}
$$

As $\gamma_{C}$ and $\gamma_{P}$ denote the trend rate of the evolution in the cost of the equipment (see Equation 5) and the evolution of energy prices. $\sigma_{\mathrm{C}}$ and $\sigma_{\mathrm{p}}$ are the respective deviations, which determine the degree of random volatilities around patterns. $d z_{C}$ and $d z_{p}$ are random variables that follow the Wiener process in which $d z_{i}=\varepsilon \sqrt{d t}$ with $\varepsilon \sim N(0.1)$.

Assuming, for simplicity, an investment of CED saves one unit of energy per year. The monetary value of energy savings (M) therefore equal to:

$$
M(t)=P_{t} / C_{t}
$$

Admitting uncertainty of economic agents about the perceived costs of equipment and future energy prices, we set the geometric Brownian motion of the perception of future benefits of energy savings as follows: 
Citation: Jridi O (2017) Energy Paradox: Simulation and Policy Recommendations for the Case of Solar Water Heater. J Environ Anal Toxicol 7: 480. doi: $10.4172 / 2161-0525.1000480$

Page 3 of 6

$d M_{t}=M_{P} d P_{t}+M_{C} d C_{t}+\frac{1}{2}\left[\left(M_{P P}\left(d P_{t}\right)^{2}+M_{C C}\left(d C_{t}\right)^{2}+2 M_{P C}\left(d P_{t}\right)\left(d C_{t}\right)\right)\right]$

Substituting Equation (7) and (8) into Equation (9), we obtain:

$$
d M\left(P_{t}, C_{t}\right)=\left(\gamma_{P}-\gamma_{C}+\sigma_{C}^{2}-\rho \sigma_{P} \sigma_{C}\right) M_{t} d t+\sigma_{P} M_{t} d z_{P}-\sigma_{C} M_{t} d z_{C}
$$
et $d z_{C}$

With $d z_{i}$. $D z_{j}=d t$ if $i=j$ and $\rho d t$ if not, where $\rho$ is the correlation $d z_{P}$

Given the lack of correlation between $d z_{p}$ et $d z_{C}(\rho=0)$, therefore we conclude that $\mathrm{M}_{\mathrm{t}}$ follows a geometric Brownian motion process with a trend rate $\gamma=\gamma_{P}+\left(-\gamma_{C}+\sigma_{C}^{2}\right)$ and a standard deviation $\sigma=\sigma_{\mathrm{P}}-\sigma_{\mathrm{C}}$.

Ultimately, the development of the benefits of energy savings results in the parameter $\gamma$, that is the sum of the effect of inflation of energy price $\gamma_{P}$ and the effect of the experience curve. If these effects are significant, pending offer, with greater certainty, the opportunity to generate higher cash flows, by unit of energy saved, relative to the current date unit.

\section{The option value and the decision rule}

Referring to the standard rule of the investment decision, a representative agent adopts energy-efficiency investment if the present value of the benefits of energy savings is greater than the purchase and installation cost. On the part of the inflows, we assume that energy efficiency equipment can save a fraction $\lambda(0<\lambda \leq 1)$ with respect to the energy consumption of the ulterior equipment, not supposed to be energy efficient.

Note that if $\lambda=1$, the investment of control of energy demand will generate $100 \%$ of energy savings, as the standards set by the engineers. For values of $\lambda$ less than unity, the investment will generate less energy savings than those who were planned by engineers.

Accepting the irreversibility of this decision, once the investment is adopted at year T, the cost of investment stagnates at $C_{T}$ and just $P_{t}$ continues to follow a stochastic way, for all $t>T$. After the completion of the investment, the present value of the benefits of energy savings, discounted at rate $r$ over a period of supposedly infinite life, so follows the evolution of $P_{t}$ the rate $\gamma_{\mathrm{P}}$ :

$$
\frac{\lambda P_{t}}{\left(\mathrm{r}-\gamma_{\mathrm{P}}\right)}>C_{T}
$$

However, basing on calculation of the standard approach counts on the existence of the energy paradox: that of the sub-adoption of the profitable investments of CED. Supporting the thesis that this paradox is not due to irrational behavior or a variety of market failures, we argue that the potential investor postpones adoption of equipment at a time allowing it to maximize its option value. The research for the optimal date of investment in energy efficiency, for a representative agent, so through maximizing this option value.

$$
\mathrm{V}(S)=\max E\left[S_{t} e^{(-r T)}-C\right]
$$

Where $\mathrm{E}$ is the expectation, $V(S)$ is the option value related to this expectation and $T$ denotes the optimal adoption date of the investment. In solving the problem of valuation of the option value, we use the dynamic programming approach. We seek to establish the optimal date from the equation of benefits of investing in energy efficiency, which is simply the Bellman equation for our study:

$$
r V d T=E(d V)
$$

With the homogeneity of degree one in the price of energy, we set the functional form of the option value as follows:

$$
V(P, C)=C v\left(\frac{P}{C}\right)
$$

The resolution of this equation involves the application of Ito's lemma:

$$
d V=C \frac{d V}{d S} d S+\frac{1}{2}\left(C \frac{d^{2} V}{d S^{2}}\left(d S^{2}\right)+V d C\right.
$$

Substituting Equation (15) into (14), for applying the expectation E on the differential equation of $\mathrm{V}$, we obtain:

$$
\left(\mathrm{r}-\gamma_{\mathrm{C}}\right) V d t=\gamma S \frac{d V}{d A} d t+\frac{1}{2} \sigma^{2} S^{2} \frac{d^{2} V}{d A^{2}} d t
$$

With $\sigma^{2}$ the variance of the increment $d S / S$. This equation can be reset as follows:

$$
\gamma S \frac{d V}{d A} d t+\frac{1}{2} \sigma^{2} S^{2} \frac{d^{2} V}{d A^{2}} d t-\left(r-\gamma_{C}\right) V d t=0
$$

In comparison with the Black-Scholes' equation (without fish jump), we note that the discount rate similar to the option value is increased from $r$ to $\left(r-\gamma_{C}\right)$. Recalling that $\gamma_{C}$ measures the tendency of the cost of equipments $\left(\gamma_{C}<0\right)$, so we conclude that agents expect more value option in the presence of the dynamics of learning by doing.

A second comparison with the equation of Ansar [7], which incorporates the technique of a fish jump down (with an average arrival rate equal to $\lambda$ ) to measure the effect of expiration of temporary subsidies, we note that the discount rate similar to the option value is increased from $(r+\lambda)$ to $\left(r-\gamma_{C}\right)$. The absence of the effect of the dynamics of learning by doing in anticipation of the benefits of energy savings is a tangible proof of the non-explicit integration of this effect in the process of changing economies energy.

The analytical solution of the differential Equation (17) is given by:

$V(S)=A S^{\beta}$

Solving this equation allow for two roots. As the possibility of investing today is useless $(V(O)=0)$, we eliminate the negative root and we keep the $\operatorname{root} \beta_{1}$ with $\beta_{1}>1$ :

$$
\beta_{1}=\frac{1}{2}-\frac{\left(\gamma_{\mathrm{p}}-\gamma_{C}+\sigma_{C}^{2}-\rho \sigma \rho \sigma_{c}\right)}{\left(\sigma_{p}^{2}+\sigma_{C}^{2}-2 \rho \sigma \rho \sigma_{c}\right)}+\sqrt{\left(\frac{\left(\gamma_{\mathrm{p}}-\gamma_{c}+\sigma_{c}^{2}-\rho \sigma \rho \sigma_{c}\right)}{\left(\sigma_{p}^{2}+\sigma_{C}^{2}-2 \rho \sigma \rho \sigma_{c}\right)}-\frac{1}{2}\right)^{2}+2 \frac{\left(\mathrm{r}-\gamma_{C}\right)}{\left.\sigma_{p}^{2}+\sigma_{C}^{2}-2 \rho \sigma \rho \sigma_{c}\right)}}
$$

From the solution $\beta_{1}$ we get, easily, the threshold of the updated energy economies gain $S^{*}$, for which the optimal value of option is reached, and the constant $A$ of Equation (18):

$$
\begin{aligned}
& S^{*}=\frac{\beta_{1}}{\beta_{1}-1} C \\
& A=\frac{S^{*}-C}{\left(S^{*}\right)-\beta_{1}}=\frac{\left(\beta_{1}-1\right)^{\beta_{1}-1}}{\left(\beta_{1}\right)^{\beta_{1} C \beta_{1}-1}}
\end{aligned}
$$

Ultimately, we can identify the option value and the optimal decision rule. For a representative agent, investment will only be made if the ratio $P_{t} / C_{t}$ exceeds the threshold of updated energy-saving benefits $S^{*}$ :

Note that the achievement of this optimum option value is often related to a more demanding than the general status of the NPV. The investment of energy renovation will not take that option if its optimal value is reached, even if its NPV is positive. This analytical result provides, therefore, a fundamental explanation for the paradox of energy efficiency, defined by the non-adoption of energy renovation investments in positive NPV $[4,7,16]$ for similar explanation. 


\section{The heterogeneity of potential energy savings}

At this level of modeling, formalizing the problem of MDE equipment sub adoption break with the foundations of the new technology diffusion theory, for all members of the target population have the same option value. To circumvent this limitation and create a more realistic diffusion model, we integrate the heterogeneity of potential energy savings of households by specifying the parameter $\lambda_{i}$ with the slope of household $i$ to the adoption of these equipments.

Formally, we assume that this parameter follows a normal distribution in the cardinal of the target population, with a specific average and standard deviation of technical characteristics of the equipment, as estimated by the engineers (Figure 1). This technique allows us to trace the sigmoid curve diffusion path, as suggested by the theory of diffusion of innovations, from the innovators (with $\lambda$ high) to laggards (with $\lambda$ low). Figure 1 show, respectively, hypothetical and standardized distributions of adoptions by energy saving potential. Via this second approach we show the energy paradox by calculating the EEG standards between engineers and actual barriers to energy efficiency.

\section{Deduction of minimum rate of return required}

Suppose that a representative agent adopts CED equipment in the year T. After a year of investment, we reset the equation of updated energy savings benefits as follows:

$$
S_{t}=\frac{M(T+1, T)}{r-\gamma_{P}}
$$

Since the optimal decision rule for the adoption of energy equipment is governed by Equation (21), the level of services required and updated after a year of investment is therefore equal:

$$
M(T+1, T)=\left(\frac{\beta_{1}}{\beta_{1}-1}\right) C_{T}\left(r-\gamma_{P}\right)
$$

We conclude that the benefits of energy savings generated by this investment decision is based on the induced current value through investment $\mathrm{S}^{*}$ and the conventional hurdle rate of Hassett and Metcalf indicated by $\left(r-\gamma_{\mathrm{p}}\right)$. The minimum rate of return required $R$ is determined by the discount rate that equates the present value of the investment at initial cost:

$$
\frac{M(T+1, T)}{R-\gamma_{P}}=C_{T}
$$

Substituting Equation (23) in Equation (24), the minimum required rate of return is expressed as follows:

$$
R=\left(\frac{\beta_{1}}{\beta_{1}-1}\right)\left(r-\gamma_{P}\right)+\gamma_{P}
$$

\section{Results}

We start by estimating the coefficients of the Bass equation (Equation 3) which allows the adjustment of cumulative adoptions process in the case of economic lamps and solar water heaters in Tunisia. This adjustment allows us later to estimate the function of learning by doing in its temporal dimension (Equation 4). For all of these estimates, the method of nonlinear least squares is the most reliable in the case of non-linear functions [16-18]. Table 1 summarizes the results of these estimates.

The estimation of the learning by doing function table on significant experience indices. This series of costs obtained gives us a reliable parameterization of the stochastic process of the evolution of the costs of the equipments, after the calculations of trend and variance parameters. Parameters of the stochastic evolution of electricity prices processes are directly calculated from the series of changes in average electricity tariffs. Table 2 provides an overview of these parameters.

After calculating these parameters, we can simulate the endogenous model coefficients $\left(\beta_{1}, S^{*}\right.$ et $\left.A\right)$. In contemplation of not having an eternal waiting to invest, we simulate for each device the lower bound of discount rate $r_{\mathrm{Min}}$, which allows to obtain the sustainable and optimal option value [1]. From these parameters, we can easily get the minimum rate of return $R$ required by a representative household to adopt energysaving equipment. This rate is defined as the discount rate that equates the current value of investment to initial cost.

$$
R=\left(\frac{\beta_{1}}{\beta_{1}-1}\right)\left(\mathrm{r}_{\text {Min }}-\gamma_{P}\right)+\gamma_{P}
$$

The simulation results illustrate a high hurdle rate. These high requirements are explained by taking into account the effects of uncertainty and learning by doing. In fact, according to the dynamics of the model, a potential investor's interest to see a worthwhile investment, as it anticipates lower equipment costs, as a result of

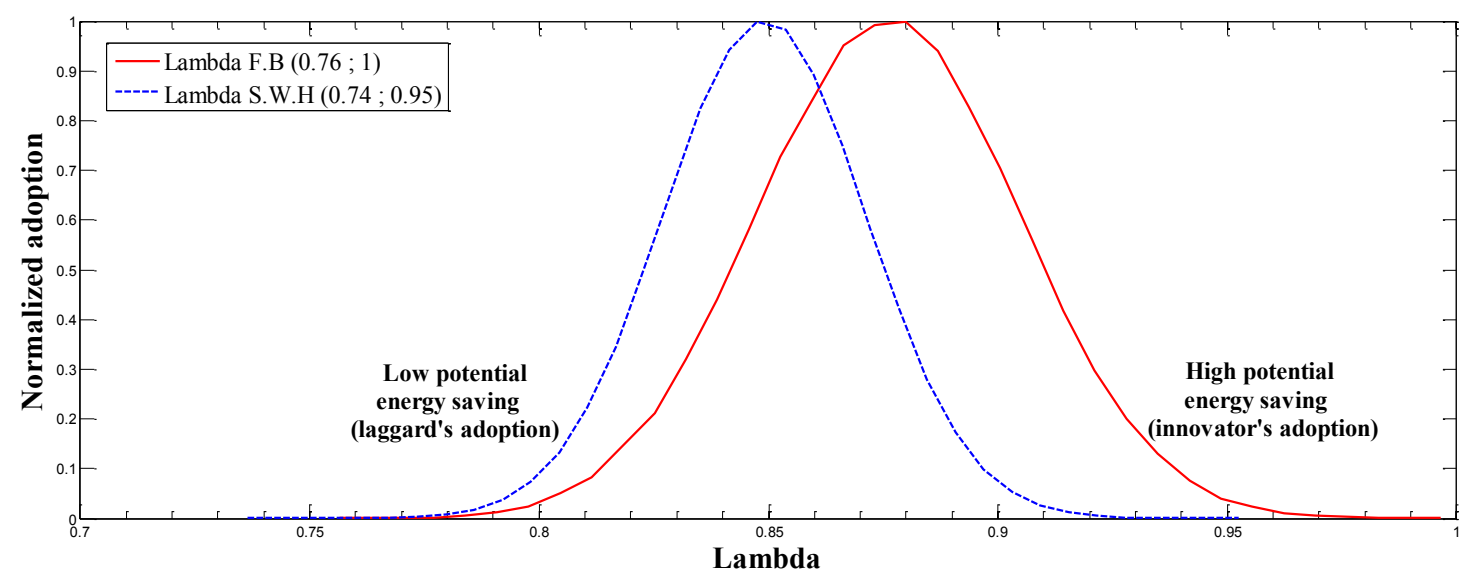

Figure 1: Potential energy saving distribution. 
Citation: Jridi O (2017) Energy Paradox: Simulation and Policy Recommendations for the Case of Solar Water Heater. J Environ Anal Toxicol 7: 480. doi: $10.4172 / 2161-0525.1000480$

Page 5 of 6

\begin{tabular}{|l|c|c|c|c|c|}
\hline & \multicolumn{4}{|c|}{ Bass Model } & \multicolumn{2}{c|}{ Learning by doing function } \\
\hline & $\boldsymbol{M}$ & $\boldsymbol{p}$ & $\boldsymbol{q}$ & $\boldsymbol{R}^{\mathbf{2}}$ & $\boldsymbol{R}^{\mathbf{2}}$ \\
\hline Solar Water Heater & 2810 & $0.001\left(12.9^{*}\right)$ & $0.185(1.84)$ & 0.836 & $-0.016\left(-7.27^{*}\right)$ \\
\hline
\end{tabular}

$\left({ }^{*}\right)$ Indicates that the statistics are significant at $1 \%$.

Table 1: Estimated exogenous parameters to stochastic model

\begin{tabular}{|c|c|c|c|c|c|}
\hline \multirow[t]{2}{*}{ Exogenous variables } & $\gamma_{\mathrm{C}}$ & $\sigma_{C}^{2}$ & $\gamma_{\mathrm{P}}$ & $\sigma_{P}^{2}$ & $r_{\text {Min }}$ \\
\hline & -0.025 & 0.001 & 0.052 & 0.07 & 0.07 \\
\hline \multirow{2}{*}{ Endogenous variables } & $\beta_{1}$ & $S^{*}$ & $A$ & $R$ & $R$ \\
\hline & 1.1524 & 7.5611 & 0.7346 & 0.018 & 0.1881 \\
\hline
\end{tabular}

Table 2: Parameters simulation of stochastic processes.

learning by doing. In this context, with a high learning by doing effect $|b|=0.016$, agents have interest in increasing their demands for a high option value $\left(S^{*}=7.5611\right)$. To reach this threshold, they postpone their decisions to adopt solar water heaters, because they require for a rapid actualization process, in other words, the requirement of a high rate of return $(\mathrm{R}=18.81 \%)$. The staggering of the adopted decisions of these equipments involves under adoption of such equipment that is energy efficiency gap relative to estimations of engineers. The simulations of these gaps are the object of the second sub-section.

At this level of modeling, we note that all estimates are made at the median points, in case of a representative agent. With this model's structure, all members of the potential market (household and investor) have the same option value. These agents are investing simultaneously once the actualized benefits of energy savings increase and reach the critical threshold. To skirt this limit and create more realism to the model, we internalize the heterogeneity of the potential for energy savings for households. We specify the parameter $\lambda_{i}$ with the energy saving potential of household $i$. On the part of receipts, we assume that equipment permit to save a fraction of energy saving $\lambda_{i}\left(0<\lambda_{i} \leq 1\right)$, relative to the standards set by the engineers. Formally, we assume that this parameter is normally distributed in the cardinal of potential investors, with a specific mean and standard deviation of the specific technical characteristics of the equipment, as estimated by the engineers Ref $[8,9]$ for a similar approach. Early investors are those with the highest energy saving potential (high $\lambda_{i}$ ) and the last investors are those with the lowest potential energy saving (low $\lambda_{\mathrm{i}}$ ). With such formalization of the problem, each agent adopts energy-saving equipment if its own optimum option value $\mathrm{S}_{\mathrm{i}}^{*}$ is reached. According to the mathematical formulation of the problem, the lower limit $r$ _Min which allows having a sustainable option value is groped based on having a solution $\beta_{1}$ of Equation (21) greater than one. Below this lower born $r_{-}$Min, the solution $\beta_{1}$ is less than one, because the term of the drift of the option value $\gamma=\gamma_{\mathrm{P}}+\left(-\gamma_{\mathrm{C}}+\sigma_{\mathrm{C}}^{2}\right)$ exceeds the discount rate. In this case, the digital solution A of Equation (23) is not calculable and the optimal option value $S^{*}$ is negative. The wait for investing is eternal.

\section{Discussion of Policy Effects}

The objective of this part is to conduct simulations on the effects of the instruments of energy policy. We assume that the goal of any political intervention in the energy-saving equipments markets is to correct the energy efficiency gap and to reach the level of diffusion estimated by engineers' standards; we take it as a reference scenario. In the first case, we simulate the effect of a subsidy for the purchase of equipment.
By simulating, after a year, the effect of a grant of $10 \%$ on the purchase of energy-saving equipment, we find that the actualized benefits of energy savings $S_{i \text { sub }}$ register instantaneous and proportional increases to past performance $S_{i}$. According to the dynamics of the model, an increase in these weakened benefits of option values required $S_{i s u b}^{*}$, which will be attainable with less waiting. We were expecting an increase of decisions of equipment's adoptions, and a reduction in energy efficiency gap. A grant of $10 \%$ on the purchase of solar water heaters significantly helps reduce the energy efficiency gap, which goes from $18.5 \%$ to $6.65 \%$, that is a sub diffusion of $2247 \mathrm{~m}^{2}$ of solar water heaters installed.

Since the subsidy for the equipment's purchase does not fully correct energy efficiency gap [19] for similar results), we simulate the effect of a second instrument of energy policy, that of taxing energy tariffs (noted tax).

According to the dynamics of the model, once the investment is adopted on the date, costs are irreversible. Subsequent to the stagnation of those costs to $C_{T}$, households enjoy the benefits of their energy savings only with changes in energy prices. After investment, $S_{t}$ therefore continues to follow the stochastic path $P_{t}$ which is more decisive in the assessment of energy savings benefits. We therefore expected a higher increase in benefits of energy saving which speeds reaching critical thresholds required by households. Subsequently, we expect a more rapid increase in adoptions, relative to the scenario of subsidies for the purchase of equipments. A taxation of $10 \%$ of electricity tariffs significantly contributes to the integral correction of energy efficiency gap, observed relative to engineers' estimations. Simulations predict an over adoption of $1138 \mathrm{~m}^{2}$ of solar water heaters.

In a third alternative, we simulate the simultaneous effect of the two previous instruments (a 10\% subsidy for the purchase of equipment and a $10 \%$ taxation of energy prices). By simulating the effect of both simultaneous instruments after one year, we notice a very significant appreciation of the benefits of energy savings. According to the dynamics of the model, we expected an amplification of adoptions process of both equipments that is a correction of the energy efficiency gap. The simulation results predict an over adoption of $9244 \mathrm{~m}^{2}$ of solar water heaters. Ultimately, we urge policy makers the allocation of energy taxation to subsidize energy-saving equipments. This combined instruments policy rationalizes, in the one hand, energy consumption and directs economic agents to adopt energy-saving equipments, on the other hand.

\section{Conclusions}

The modeling challenge of the energy paradox is crystallized around 
Citation: Jridi O (2017) Energy Paradox: Simulation and Policy Recommendations for the Case of Solar Water Heater. J Environ Anal Toxicol 7: 480. doi: $10.4172 / 2161-0525.1000480$

Page 6 of 6

the rationalization what it seems to be irrational behavior regarding the non adoption of profitable energy saving investments. The under adoption of profitable investments in energy saving is mainly due to the maximization of option values. In this objective, the economic agent requires high hurdle rates allowing it to equalize the present value of future energy savings benefits to its expected benefits (optimal option value).

Formally, we postulate that this option value is supported simultaneously by uncertainty of future benefits of energy saving, dynamics of learning by doing and the irreversibility of the investment cost. The model's parameters estimation expects a strong significance of these explanatory factors. The simulations show that for adopt a solar water heaters, agents require an average hurdle rate of $18.81 \%$. These strong profitability requirements explain the sub adoption of energysaving investments. Beyond this, the simulations predict a sub adoption of $5062 \mathrm{~m}^{2}$ of installed solar water heaters, in the horizon of 2040 . Therefore, these simulations justify political intervention to correct energy efficiency gaps.

Simulations of the effects of the energy policy's instruments prove the ineffectiveness of isolated subsidy instruments to the purchase of energy-saving equipments, which can correct only a portion of energy efficiency gap, and the efficiency of energy prices taxation, which fully correct these gaps. By simulating the combined effect of these two instruments, we urge policy makers to allocate of energy taxation revenues to fund subsidizing of the energy-saving equipments. The dual effect of this policy is summed up, on the one hand, in the rationalization of household energy consumption, under the effect of the increase of energy tariffs, elsewhere, encouraging the adoption of saving-energy equipments under the effect of their subsidies.

\section{References}

1. Rehdanz K (2007) Determinants of residential space heating expenditures in Germany. Energy Economics 29: 167-182.

2. Weiss M, Patel MK, Junginger M, Blok K (2010) Analyzing price and efficiency dynamics of large appliances with the experience curve approach. Energy Policy 38: 770-783.
3. Sanstad AH, Blumstein C, Stoft SE (1995) How high are option values in energy-efficiency investments? Energy Policy 23: 730-743.

4. Jaffe AB, Stavins RN (1994) The energy-efficiency gap: what does it mean? Energy Policy 22: 804-810.

5. Hassett KA, Metcalf GE (1993) Do consumers discount the future correctly? Energy Policy 21: 710-716.

6. Levinson A, Niemann S (2004) Energy use by apartment tenants when landlords pay for utilities. Resource and Energy Economics 26: 51-75.

7. Ansar J, Sparks R (2009) The experience curve, option value, and the energy paradox. Energy Policy 37: 1012-1020.

8. Rogers EM (1983) Diffusion of Innovations. Free Press, New York.

9. Rogers EM (1995) Diffusion of Innovations. Free Press, New York.

10. Bass FM, Wind J (1995) Introduction to the special issue: empirical generalizations in marketing. Marketing Science 14: G1-G5.

11. Bass FM, Krishnan TV, Jain DC (1994) Why the Bass model fits without decision variables. Marketing Science 13: 204-223.

12. Srinivasan V, Mason $\mathrm{CH}$ (1986) Nonlinear least squares estimation of new product diffusion models. Marketing Sci 5: 169-178.

13. Jridi O, Bargaoui SA, Nouri FZ (2015) Household preferences for energy saving measures: Approach of discrete choice models, Energy and buildings 103: 38-47.

14. Cameron TA (1985) A Nested Logit Model of Energy Conservation Activity by Owners of Existing Single Family Dwellings. The Review of Economics and Statistics 67: 205-211.

15. Demidenko E (2008) Criteria for unconstrained global optimization, J. Optim Theory Appl 136: 375-395.

16. Hassett KA, Metcalf GE (1999) Investment with uncertain tax policy: does random tax policy discourage investment?. The Economic Journal 109: 372-393.

17. Diaz-Raineya I, Ashtonb JK (2009) Domestic Energy Efficiency Measures Adopter Heterogeneity and Policies to Induce Diffusion. Working Paper SSRN pp 1-8.

18. Hausman JA (1979) Individual discount rates and the purchase and utilization of energy-using durables. Bell Journal of Economics 10: 33-54.

19. Mahapatra K, Gustavsson L (2008) An adopter-centric approach to analyze the diffusion patterns of innovative residential heating systems in Sweden. Energy Policy 36: 577-590. 